УДК 316

$10.17213 / 2075-2067-2020-4-115-126$

\title{
УПРАВЛЕНИЕ СОЦИАЛЬНО-ЭКОНОМИЧЕСКОЙ БЕЗОПАСНОСТЬЮ РОССИЙСКОГО ОБЩЕСТВА В УСЛОВИЯХ КРИЗИСА МИРОВОЙ ЭКОНОМИКИ: ПОСТПАНДЕМИЧЕСКИЕ СЦЕНАРИИ
}

\author{
(C) 2020 г. А. В. Верещагина *, А. В. Рачипа *, П. В. Таранов** \\ *Южсный федеральный университет, г. Ростов-на-Дону, Россия \\ **Ростовский государственный экономический университет (РИНХ), \\ 2. Ростов-на-Дону, Россия
}

Целью исследования является анализ дискурсивного пространства, сформировавшегося в области изучения сочиально-экономической безопасности российского общества и управления ею в условиях мирового экономического кризиса, вызванного пандемией COVID-19.

Методологическую базу исследования представляют принцииы и положения, сложившиеся в рамках теории безопасности в пространстве различных дисциплинарных практик (экономических, сочиологических, философских и т.д.), а также теоретические установки сиенарного подхода, применение которого в сфере управления безопасностью общества позволяет не только выявить и предотвратить возможные риски, но и трансформировать их в состояние перспективных возможностей.

Результаты исследования. Анализ экспертных оченок и прогнозов относительно возможных сиенариев сочиально-экономического развития российского общества в новом потпандемическом мире показал широкий разброс позищий и мнений. В большиснтве случаев исследователи пессимистично настроены относительно постпандемического будущего российской экономики и развития социальных процессов. Причина видится в несоответствии управленческой системы давно изменившимся реалиям сочиильно-экономического пространства циифрового мира, а также принциипам социиального государства. При имеющихся у России ресурсах (человеческих, природных и т.д.) перспективы преодоления пандемического кризиса и безопасного сочиально-экономического развития в условиях постпандемического мира представляются вполне реальными, но определяются в координатах строительства новой российской государственности. При этом крайне важно вернуться к социальному государству как реальной практике государственного управления. Этого требуют реалии пандемической ситуации, выявившие высокую опасность игнорирования неэкономических факторов и аспектов в развитии как отдельных государств, так и всего мирового сообщества.

Перспективу исследования составляет возможность и необходимость дальнейшей рефлексии экспертных оченок и управленческих практик в области обеспечения сочиильноэкономической безопасности российского общества в проекиии грядущего постпандемического мира.

Ключевые слова: сочиально-экономическая безопасность; управление сочиально-экономической безопасностью; мировая экономика; кризис; сиенарный подход; пандемия коронавируса; постпандемический мир. 


\title{
SOCIO-ECONOMIC SECURITY \\ OF RUSSIAN SOCIETY AND ITS MANAGEMENT \\ IN THE CONTEXT OF THE GLOBAL ECONOMIC CRISIS: POST-PANDEMIC SCENARIOS
}

\author{
(C) 2020 A. V. Vereshchagina*, A. V. Rachipa*, P. V. Taranov** \\ *Southern Federal University, Rostov-on-Don, Russia \\ **Rostov State University of Economics (RSUE), Rostov-on-Don, Russia
}

The purpose of the study is to analyze the discourse space that has formed in the study of the socio-economic security of Russian society and its management in the context of the global economic crisis caused by the COVID-19 pandemic.

The methodological basis of the research is represented by the principles and provisions that have developed within the framework of security theory in the space of various disciplinary practices (economic, sociological, philosophical, etc.), as well as the theoretical principles of the scenario approach, the application of which in the field of social security management allows not only to identify and prevent possible risks, but also transform them into a state of promising opportunities.

Research results. An analysis of expert assessments and forecasts regarding possible scenarios for the socio-economic development of Russian society in the new pandemic world showed a wide range of positions and opinions. In most cases, researchers are pessimistic about the post-pandemic future of the Russian economy and the development of social processes. The reason is seen in the inconsistency of the management system with the long-changed realities of the social and economic space of the digital world, as well as the principles of the welfare state. Given Russia's resources (human, natural, etc.), the prospects for overcoming the pandemic crisis and safe socio-economic development in a post-pandemic world seem quite real, but they are determined in the coordinates of building a new Russian statehood. At the same time, it is extremely important to return to the welfare state as a real practice of public administration. This is required by the realities of the pandemic situation, which revealed a high danger of ignoring non-economic factors and aspects in the development of both individual states and the entire world community.

The prospect of the research is the possibility and the need for further reflection of expert assessments and management practices in the field of ensuring the socio-economic security of Russian society in the projection of the coming post-pandemic world.

Key words: socio-economic security; socio-economic security management; world economy; crisis; scenario approach; coronavirus pandemic; post-pandemic world.

Введение. Проблема безопасности общества достаточно давно и прочно обосновалась в системе социально-гуманитарного знания. Ей посвящали свои труды философы, политологи, экономисты, психологи, историки и социологи. В ряде случаев ученые пытались охватить проблемы безопасности в комплексном виде и в междисциплинарном предметном пространстве [1]. Исследовательский дискурс безопасности разви- вался по разным направлениям: с позиций влияния фактора глобализации и столкновения цивилизаций, межэтнических конфликтов и социальной поляризации в обществе, экологических катастроф и демографической динамики. В фокусе внимания ученых зачастую оказывался вопрос о степени влияния на безопасность общества внутрирегиональных и межрегиональных факторов риска [2], о соотношения рынка и государс- 
тва в контексте мировых трендов экономического устройства [3].

Ситуация с пандемией COVID-19, обозначившаяся в начале 2020 года, с одной стороны, актуализировала ранее поднимавшиеся на уровне научно-исследовательского поиска аспекты и проблемы безопасности общества, поскольку затронула абсолютно все сферы общественной жизни, а с другой — выявила новый пласт проблем и аспектов, который моментально попал в поле зрения ученых. Самым актуальным образом на повестке дня встал вопрос о социально-экономической безопасности общества и управлении ею. По мнению профессора РЭШ А. Обижаевой, «мировой кризис, вызванный пандемией коронавируса, сильно ускорит происходящие в мире социальные, экономические и геополитические процессы, проверив на прочность мировую финансовую систему» [4].

Таким образом, кризис мировой экономики, обозначивший пока только свои контуры, стал определяющим фактором в функционировании не только экономической системы, но и всей системы жизнедеятельности социума, провозгласив «окончательный триумф цифровой экономики» [5]. Обвал малого и среднего бизнеса, на который пришелся основной удар пандемии [6], «потянул» за собой массу других проблем, обострив ситуацию на рынке труда, отразившись на финансовом, социальном и физическом самочувствии населения. Если оценивать данную ситуацию в государственном масштабе, пандемия коронавируса, о завершении которой еще говорить рано, угрожает национальной катастрофой целому ряду стран, особенно тем, чья экономика не смогла быстро перейти на «цифровые» механизмы функционирования. Эта угроза связана с разрушением устоявшегося социально-экономического уклада, не готового к функционированию в условиях, подобных которым человеческий мир еще не знал с учетом планетарного масштаба проблемы коронавируса.

В обозначенных условиях естественным образом обозначилась ключевая для всех стран, втянутых в пандемию коронавируса и мирового эконмического кризиса, проблема управления безопасностью общества. В данной статье ввиду обозначенного как доминантного социально-экономического вектора рисков, связанных с пандемической ситуацией, угрожающих разрушительными последствиями на остальных ключевых «фронтах» социальной жизни, поднимается проблема управления социально-экономической безопасностью общества. При этом нас интересует не только и не столько ситуация реальная, уже обозначившаяся как кризисная, сколько ситуация ожидаемого постпандемического будущего. Перед системой управления на различных уровнях (глобальном, локальном), в различных сферах и отраслях экономики в ситуации мирового характера экономического кризиса стоит вопрос о том, как адаптироваться к новой социально-экономической реальности и предотвратить аналогичные риски после того, как мировое сообщество выйдет из пандемического кризиса. А выйдет оно с пониманием того, что период пандемии стал рубежом, той точкой отсчета, с которой история человеческой цивилизации будет делиться на допандемический и постпандемический этапы [7].

Социально-экономическая безопасность общества: концептуальные границы понятия. В научном пространстве сложилось немало подходов в изучении социально-экономической безопасности, а также экономической, которая не рассматривается учеными изолированно от комплекса проблем социального, политического, технологического, духовного и иного характера, будучи детерминированной ими и оказывая значительное влияние на все сферы общественной жизни [8].

Экономическая безопасность является ключевой характеристикой социально-экономической системы общества, и ученые зачастую используют данной понятие как идентичное социально-экономической безопасности, но в ряде случаев, как отмечают исследователи, социально-экономическая безопасность индикатируется по ключевым макроэкономическим показателям, т.е. по сути сводится к экономической безопасности, а социальная составляющая данного феномена рассматривается, как его направление [9].

Тем не менее, понятия экономической безопасности и социально-экономической безопасности следует различать. И если первое означает «состояние, представляющее 
отсутствие опасности, защищенность экономики, позволяющее субъектам экономической деятельности, будь то государство, регион, предприятие или иной экономический субъект, суверенно действовать, развиваться, нормально и бесперебойно выполнять свои функции» [8], то второе, выходя за рамки сугубо экономической детерминированности, содержит в себе значительный социальный контекст. Так, согласно мнению Л.Н. Добрыниной, социально-экономическая безопасность определяется как состояние экономики и различных ее институтов, позволяющее экономической системе безболезненно реагировать на возникающие внутренние и внешние угрозы, достигать заданных индикаторов экономической безопасности, а также обеспечивать гарантированную защиту интересов граждан, хозяйственных субъектов, общества и государства с учетом динамично меняющейся среды [10].

Нам импонирует новый методологический подход к экономической безопасности, разработанный российскими учеными для ее осмысления в национально-государственном масштабе и базирующийся на концепции витальности, в рамках которой экономическая безопасность рассматривается как функция жизнеобеспечения и развития социальной системы под названием «национальная экономика» [11]. Такой подход позволил авторам предложить стратегию выявления и профилактики рисков и угроз для национальной экономики страны, а также механизм управления рисками социально-экономического развития.

Не вдаваясь в дальнейший анализ сложившихся подходов, направлений, определений социально-экономической безопасности в системе социально-гуманитарного знания, предложим собственное видение понятийных границ, в рамках которых можно анализировать социально-экономическую безопасность с позиций реалий современной эпохи.

Если взять за основу системный подход к интерпретации безопасности, в рамках которого данный феномен рассматривается как состояние социальной системы, уровень ее равновесия и способности к устойчивому воспроизводству основных системных элементов, обеспечивающих ее функционирование [12], то экономическая безопасность мо- жет интерпретироваться как такое состояние экономической системы общества, которое обеспечивает ее устойчивое функционирование и способность противостоять внешним и внутренним вызовам и угрозам посредством воспроизводства основных системных элементов. К ним мы относим: экономическое сознание, экономическую культуру, экономическое поведение, экономическую политику и экономические практики. Эти системные элементы, каждый из которых имеет свою индикативную характеристику, в формате комплексного взаимодействия определяют характер функционирования экономической системы общества, ее жизнеспособность и соответственно безопасность.

Эффективность экономической системы в координатах ее безопасного функционирования определяется эффективностью системы управления. В свою очередь, управленческая эффективность в системе обеспечения экономической безопасности общества определяется социальной эффективностью теми индикаторами, которые отражают социальный эффект от деятельности акторов в системе экономических отношений. Эти индикаторы выражаются в уровне и стабильности экономических доходов населения, динамике рынка трудовой занятости и уровне безработицы, характере социального неравенства и степени социальной поляризации, наличие устойчивого среднего класса и социального самочувствия населения, а также рядом других социальных показателей, в своей совокупности отражающих состояние социально-экономической безопасности государства и общества.

На основе уже представленного выше базового понимания безопасности и ее социально-экономических индикатив можно предложить определение социально-экономической безопасности как способности общества (социальной системы) противостоять внешним и внутренним вызовам и угрозам посредством устойчивого функционирования и воспроизводства экономической системы общества.

Управление социально-экономической безопасностью в российском обществе в условиях кризиса мировой экономики: постпандемические сценарии. Вопросы управле- 
ния социально-экономической безопасностью общества не раз становились предметом научного исследования [13], и учеными немало сделано в этом направлении в рамках предложения системных моделей, стратегических подходов и иных методологических стратегий как ориентиров для практики управления социально-экономическими процессами в пространстве обеспечения безопасного функционирования социальной системы. Однако пандемия COVID-19 со всей очевидностью обнаружила необходимость переосмысления прежних моделей и стратегий управления, сложившихся в допандемическом мире и оказавшихся слабо адаптированными к вызовам цифровой эпохи с крайне противоречивыми тенденциями глобализации. Последняя как объективный факт эволюции мирового сообщества уже не только не имеет «обратной дороги», но и вызывает весьма неоднозначные суждения и оценки со стороны научного сообщества в плане перспектив глобализирующегося мира и управления им. Ее плюсы и минусы самым очевидным образом обнаружились именно в период коронавирусной пандемии, когда ее стремительное распространение в планетарном масштабе стало импульсом для объединения усилий международного сообщества с целью противодействия пандемии на уровне профилактических мер и управленческих стратегий правительств государств.

Что следует вынести российскому государству и обществу из сложившейся пандемической ситуации в плане управления социально-экономической безопасностью в условиях встроенности российской экономической системы в мировую экономику и глубокой зависимости от нее? Во-первых, обнаруживают себя в еще более сильном болевом эффекте прежние проблемы российской экономики, и до пандемии угрожавшие социально-экономической безопасности общества низкими темпами экономического роста, примитивизацией экономической структуры, высокой энергосырьевой зависимостью, крайней технологической отсталостью индустриального сектора, оттоком капитала из страны, дефицитом инвестиций, невысокой инновационной активностью при высоком уровне территориальной дифференциации [14]. Во-вторых, переход к цифровой экономике стал более чем очевидным для все- го мирового экономического пространства, что определило необходимость пересмотра основ экономической системы и для российского государства. По тому, как активно осуществляется переход на онлайн-образование в современной России на данный период, можно судить о том, что государство всерьез задумалось о цифровой экономике при всем том, что цифровизация образования, по мнению экспертов, несет не только явные плюсы, но и минусы, угрожающие снижением качества образования и его конкурентоспособности в координатах мирового образовательного пространства [15].

Ситуация пандемии COVID-19, в каждом отдельном государстве обнаружившая свои проблемы, болевые точки, а также перспективы дальнейшего развития, стала предметом пристального внимания экспертов, попытавшихся не только осмыслить реалии пандемического мира, но и «заглянуть» за его пределы, спрогнозировать сценарии будущего постпандемического мира с учетом перспектив, имеющихся в арсенале российской экономической системы для адаптации к этому новому миру.

Надо заметить, что сценарный подход уже достаточно активно применяется российскими учеными и экспертами в сфере управления для прогнозирования возможных вариантов развития процессов и явлений в той или иной сфере в совокупности причинно-следственных связей, определяющих траекторию ее развития [16]. Применение сценарного подхода в сфере управления ориентировано на анализ возможных рисков и перспективу их предотвращения, снижения их негативных воздействий, предотвращения их фатального характера и даже перевода в состояние перспективных возможностей, что вполне реально в ситуации понимания будущего и его рисков [17].

Какие же сценарии экономического развития российского общества в постпандемическом мире предлагаются экспертами и какие управленческие рычаги при этом следует задействовать прежде всего?

Начнем с того, что становление постпандемического мира рассматривается экспертами как проект, слабо прогнозируемый с точки зрения расстановки сил на международной арене и соответственно места России в но- 
вом мире. Стоит согласиться, что пандемия COVID-19 есть вызов всему миру не только и не столько экономический и управленческий, сколько цивилизационный, аналогичный, пусть и не в таких масштабах, эпидемии чумы («Черной Смерти») середины XIV столетия, которая вызвала мощные ускорительные процессы и сдвиги по всей Европе в области экономических, духовных, политических, технологических, культурных, гендерных и иных практик [18]. Очевидно, что экономические издержки пандемии будут самыми разными для отдельных государств (для России они прогнозируются в диапазоне от 5,5\% до 6,6\% ВВП) [18], но, возможно, именно эти экономические потери послужат импульсом для принятия управленческих решений, которые позволят российскому государству выйти за пределы инерционной траектории экономического развития и осознать неизбежность перестройки всей системы производственных отношений, отсталость которых и спровоцировала внушительные финансовые и экономические потери в период пандемии [19].

При всем том, что российское государство пытается регулировать пандемическую ситуацию, эксперты оценивают предпринятые антикризисные меры, составившие в целом около 2,5\% ВВП, как недостаточные, тем более, с учетом того, что часть издержек была переложена на «плечи» частного бизнеса [20].

Очевидно, что классические (денежные, бюджетные) меры регуляции создавшейся пандемической ситуации неадекватны совершенно нетипичному экономическому кризису, не связанному с факторами экономической политики, а потому эксперты предлагают три возможных сценария среднесрочного развития ситуации с соответствующим набором мер и действий со стороны властных структур [20]:

1) оптимистический, связанный с выходом из кризисной ситуации с минимальным количеством инфицированных коронавирусом к концу лета и восстановлением докризисной экономической активности населения;

2) умеренный, когда будет установлен контроль над эпидемией к середине 2021 года при снятии основных ограничений на экономическую деятельность, но с сохранением межрегиональных и межгосударственных ограничений в сфере торговли и туризма, что будет служить сдерживающим фактором восстановления экономики;

3) пессимистический, отодвигающий установление контроля над эпидемией за горизонт 2021 года при сохранении в течение всего периода пандемии вспышек эпидемии в различных участках земного шара и соответственно большей части ограничений на экономическую активность в международном пространстве и на внутрирегиональном уровне российского государства.

По какому сценарию будет развиваться ситуация, сложно сказать, но действия российского правительства, ориентированные на поддержку банковской системы, представляются неправильными экспертам, поскольку эти меры не направлены на поддержку российской экономики, приоритет следует отдать краткосрочным проектам и решениям с учетом наиболее болезненных проблем, а также поддержке малого и среднего бизнеса, который сам не справится со своими трудностями, в отличие от крупного бизнеса, имеющего в своем активе накопленные ресурсы и средства для адаптации к кризисной ситуации. Эта помощь, как полагают специалисты, должна осуществляться за счет бюджета, а не коммерческих (банковских) структур [20].

Аналитики всего мира пытаются предугадать сценарии выхода из коронавирусного кризиса, и прошедшая в Российской академии наук онлайн-сессия на тему «Постпандемический мир и Россия: новая реальность?» выявила различные точки зрения ученых по данному вопросу [21]. Согласно одной из них, высказанной академиком А. Сергеевым, необходимо создание экономики завтрашнего дня, основанной на инвестициях в хайтек, телекоммуникации, медицинскую, фармацевтическую, биотехнологическую промышленность, и особая нагрузка в данном случае ложится на российскую науку. По мнению другого академика, А. Аганбегяна, у России, которую ждет серьезнейший структурный кризис и колоссальные финансовые потери, возникает, тем не менее, уникальная возможность, преодолев кризис, перейти к социально-экономическому росту, уйдя от длительной стагнации, однако реализация этой возможности предполагает форсированное увеличение инвестиций в основной капитал и значительные вложения в человеческий капитал (экономику знаний). 
В целом ученые солидарны во мнении, что происшедшее в период коронавируса не следует рассматривать сугубо в координатах пандемической ситуации, а причина связана с сырьевым характером российской экономики и ее зависимостью от ситуации на нефтегазовом рынке [21].

Еще одну точку зрения на постпандемический мир, в том числе в российском разрезе, представил историк, профессор В. Багдасарян, проанализировавший имеющиеся в дискурсивном пространстве модели возможного миропорядка и жизнеустройства после пандемии и выделивший четыре модели с характерными названиями [22]: 1) глобальный социально-экономический крах, 2) технологический оптимизм, 3) национальное спасение и 4) планетарный тоталитаризм. Предложенные модели, как отмечает В. Багдасарян, являются чистыми моделями, выделенными для удобства исследовательской рефлексии, на практике может произойти смешение моделей, а также возврат к старой системе, но тот факт, что на наших глазах происходит смена парадигмы грядущего мироустройства, не вызывает у него сомнений, как, впрочем, и у нас. Для России пандемическая ситуация опасна тем, что она угрожает не только здоровью населения, но и усилением заданных еще до коронавирусной пандемии авторитарных интенций, а любые масштабные кризисы, как показывает история, становятся благодатной почвой для легитимации авторитарных режимов [23]. В этой связи закономерен вывод ученых о том, что перед Россией остро стоит задача более глубокого, нежели перед другими странами, переформатирования как национальной экономики, так и государственности в целом, и при этом важно учитывать, что в постпандемическом мире (который называют также постглобальным) чрезвычайное значение приобретут неэкономические факторы, что создает для нашей страны окно возможностей в глобальной системе [24]. Строительство новой российской государственности, определяемое учеными как доминантное направление на пути к новому миру, в котором Россия должна занять достойное место, предполагает включение широких слоев населения в данный процесс при полном понимании целей и задач развития государства [24]. Тогда, как не раз случалось в российской истории, поя- вится дополнительный мощный источник для решения социальных проблем - общественный энтузиазм [5].

Заключение. Социально-экономические проблемы, вызванные пандемией коронавируса, обнажили, обострили и спровоцировали в социальном «теле» каждого государства пласт специфических проблем и болезненных точек. Необходимость проведения глубокой структурной перестройки требует не только российская экономика, но и вся система регулирования мирового хозяйства, обнаружившая, по мнению ученых, высокую затратность, особенно в тех странах, которые являются лидерами в сфере производства экспортной продукции (Китай, США, Германия) и наиболее активно в период пандемии применяли протекционистские меры с целью противостояния финансовой глобализации с ее стихийным характером [19]. Однако пандемический кризис, затронувший глубинные пласты мировой экономики, стал поводом для осмысления проблем, выходящих далеко за пределы экономической системы организации мирового сообщества и отдельно взятых государств. На повестку дня были поставлены такие вопросы, как глобализация, ее природа и перспективы дальнейшего развития; свобода, права человека и судьба демократии в проекции будущего мироустройства; безопасность национальных государств и мирового сообщества; управляемость современным миром в условиях стихийных и нерегулируемых процессов глобализации.

Ученые с трудом прогнозируют варианты выхода России из пандемического кризиса. Более уверенно они пишут о других странах, отмечая, что вероятен масштабный кризис в Европе ввиду хрупкости и нежизнеспособности сложившейся на конец 2019 года экономической системы в данном регионе мира, а относительно России с ее огромными возможностями высказываются надежды на их правильное использование [4]. Для этого необходимо вернуться к социальному государству как реальной практике государственного управления. Только в этом случае ключевые социальные институты (семьи, образования, здравоохранения) смогут эффективно выполнять свои функции по воспроизводству и развитию социокультурного потенциала общества, способствуя его 
безопасному развитию, которое, как показала ситуация с пандемией коронавируса, не должно находиться в столь жесткой зависимости от экономической системы.

\section{Литература}

1. Барышев П. В. Комплексная безопасность в России: методологический подход // Власть. - 2014. - №12. - C. 9-15.

2. Верещзагина А.В. Система комплексной безопасности современного общества в контексте национальной безопасности России в условиях новых вызовов и угроз: монография / А.В. Верещагина, С.И. Самыгин, О.М. Шевченко. — М.: РУСАЙН, 2016. $152 \mathrm{c}$.

3. Гушер А.И. Вызовы и угрозы безопасности России // Мировая политика. 2014. — №1. - C. 64-75.

4. Таранов П. В., Басенко А. М. Либерализация как глобальный тренд теоретизации государственного регулирования мировой экономики // Финансовые исследования. 2012. 一 №2 (35). - C. 48-55.

5. Обижсаева $A$. Настоящее начало XXI века: как коронакризис проверит на прочность Россию и мир [Электронный ресурс]. - Режим доступа: https://www.forbes. ru/biznes/401651-nastoyashchee-nachalo-xxiveka-kak-koronakrizis-proverit-na-prochnostrossiyu-i-mir.

6. Коровкин В. Мировая экономика после коронавируса: перезагрузка? [Электронный ресурс]. - Режим доступа: https:// russiancouncil.ru/analytics-and-comments/ analytics/mirovaya-ekonomika-poslekoronavirusa-perezagruzka/.

7. Баринова В. Дыра в ВВП: чем грозит экономике гибель малого бизнеса в России [Электронный ресурс]. - Режим доступа: https://www.forbes.ru/biznes/399389-dyra-vvvp-chem-grozit-ekonomike-gibel-malogobiznesa-v-rossii.

8. Иванов И. Мир будет другим [Электронный ресурс]. - Режим доступа: https:// www.kommersant.ru/doc/4326474.

9. Климонова А.Н., Юрина Е.А. Экономическая безопасность в условиях глобализации: угрозы и возможности // Социально-экономические явления и процессы. - 2014. T. 9. - №9. - C. 58-64.
10. Долганова Я.А. Социально-экономическая безопасность региона: проблемы оценки, перспективы развития // Вестник Прикамского социального института. - 2018. №1 (79). - С. 109-113.

11. Добрышина Л. Н. Социально-экономическая безопасность: сущность, эволюция, факторы // Транспортное дело России. 2011. - №10. - C. 5-7.

12. Экономическая безопасность России: методология, стратегическое управление, системотехника: монография / кол. авторов; под науч. ред. С. Н. Сильвестрова. - Москва: РУСАЙНС, 2018. - 350 с.

13. Самызин С.И., Степанов О.В. Социальная безопасность в системе социальногуманитарного знания о безопасности // Coциально-гуманитарные знания. - 2014. №11. - С. 54-55.

14. Соложенцев Е.Д. Управление безопасностью социально-экономических систем // Проблемы анализа риска. - 2017. T. 14. - №5. - С. 6-19. [Электронный pecypc]. - Режим доступа: https://doi. org/10.32686/1812-5220-2017-14-5-6-19.

15. Ускова Т.В. Ключевые угрозы экономической безопасности России // Проблемы развития территории. — 2019. — №1 (99). C. 7-16.

16. Воденко К.В., Боровая Л.В., Ефимов A. В. Российское образование в условиях глобальной информатизации и цифровизации: социально-философский дискурс // Гуманитарий Юга России. - 2020. - Т. 9. №3. - С. 36-44.

17. Ковалев В.В., Касьянов В.В., Манучарян $A . K$. Онлайн-образование в высшей школе России: фактор разрушения или источник развития? // Гуманитарий Юга России. 2020. - T. 9. - №3. - С. 72-91.

18. Феофанов K. Е. О сценарном подходе к прогнозированию // Социологические исследования. - 2008. - №5. - С. 67-74.

19. Волков Ю.Г., Верещзагина А.В., Узунов B. B. Сценарии инновационного развития российских регионов: институционально-управленческое измерение // Государственное и муниципальное управление. Ученые записки. - 2019. - №2. - С. 35-40.

20. Кортунов А. Глобальная победа над COVID-19: мы за ценой не постоим? [Электронный ресурс]. - Режим доступа: https:// 
russiancouncil.ru/analytics-and-comments/ analytics/globalnaya-pobeda-nad-covid-19-myza-tsenoy-ne-postoim/.

21. Кузнецов A. Коронавирус как диагноз системного застоя [Электронный ресурс]. Режим доступа: https://russiancouncil.ru/ analytics-and-comments/analytics/koronaviruskak-diagnoz-sistemnogo-zastoya/.

22. Коронакризис-2020: что будет и что делать? Сценарии развития и меры экономической политики / под ред. К. Рогова. - Москва: Либеральная миссия, 2020. - 45 с.

23. Беляева C. О жизни после: эксперты заглянули в постпандемическую реальность [Электронный ресурс]. - Режим доступа: https://www.poisknews.ru/themes/ ekonomika/o-zhizni-posle-eksperty-zaglyanuliv-postpandemicheskuyu-realnost/.

24. Багдасарян В. Коронавирусный мир: постпандемические модели [Электронный ресурс]. - Режим доступа: http://www. noravank.am/rus/articles/detail.php? ELEMENT_ $\mathrm{ID}=18066$.

25. Вирусный авторитаризм [Электронный ресурс]. - Режим доступа: http:// www.eedialog.org/ru/2020/04/29/virusnyjavtoritarizm/.

26. Евстафьев Д., Ильницкий А. Предположения о грядущем мире // Россия в глобальной политике. - 2020. - №4. [Электронный ресурс]. - Режим доступа: https:// globalaffairs.ru/articles/predpolozheniya-ogryadushhem-mire/.

\section{References}

1. Baryshev P.V. Kompleksnaja bezopasnost' v Rossii: metodologicheskij podhod [Integrated security in Russia: a methodological approach] // Vlast' [Power]. — 2014. — №12. Pp. 9-15.

2. Vereshhagina A.V. Sistema kompleksnoj bezopasnosti sovremennogo obshhestva v kontekste nacional'noj bezopasnosti Rossii v uslovijah novyh vyzovov i ugroz: monografija [Complex security system of modern society in the context of national security of Russia in the context of new challenges and threats: monograph] / A. V. Vereshhagina, S.I. Samygin, O.M. Shevchenko. Moscow: RUSAJN, 2016. - 152 p.

3. Gusher A.I. Vyzovy i ugrozy bezopasnosti Rossii [Challenges and threats to Russia's security] // Mirovaja politika [World politics]. 2014. — №1. - Pp. 64-75.

4. Taranov P. V., Basenko A.M. Liberalizacija kak global'nyj trend teoretizacii gosudarstvennogo regulirovanija mirovoj jekonomiki [Liberalization as a global trend in the theorization of state regulation of the world economy] // Finansovye issledovanija [Financial research]. 2012. — №2 (35). — Pp. 48-55.

5. Obizhaeva A. Nastojashhee nachalo XXI veka: kak koronakrizis proverit na prochnost' Rossiju i mir [The present beginning of the XXI century: how the crown crisis will test the strength of Russia and the world] [Jelektronnyj resurs]. URL: https://www.forbes.ru/biznes/401651-nastoyashchee-nachalo-xxi-veka-kak-koronakrizisproverit-na-prochnost-rossiyu-i-mir.

6. Korovkin $V$. Mirovaja jekonomika posle koronavirusa: perezagruzka? [The world economy after the coronavirus reloaded?] [Jelektronnyj resurs]. — URL: https://russiancouncil.ru/ analytics-and-comments/analytics/mirovayaekonomika-posle-koronavirusa-perezagruzka/.

7. Barinova $V$. Dyra v VVP: chem grozit jekonomike gibel' malogo biznesa $\mathrm{v}$ Rossii [The hole in GDP: what threatens the economy with the death of small businesses in Russia] [Jelektronnyj resurs]. - URL: https://www.forbes. ru/biznes/399389-dyra-v-vvp-chem-grozitekonomike-gibel-malogo-biznesa-v-rossii.

8. Ivanov I. Mir budet drugim [The world will be different] [Jelektronnyj resurs]. — URL: https://www.kommersant.ru/doc/4326474.

9. Klimonova A.N., Jurina E.A. Jekonomicheskaja bezopasnost' v uslovijah globalizacii: ugrozy i vozmozhnosti [Economic security in the context of globalization: threats and opportunities] // Social'no-jekonomicheskie javlenija i processy [Socio-economic phenomena and processes]. - 2014. - Vol. 9. - №9. - Pp. 58-64.

10. Dolganova Ja. A. Social'no-jekonomicheskaja bezopasnost' regiona: problemy ocenki, perspektivy razvitija [Socio-economic security of the region: problems of assessment, development prospects] // Vestnik Prikamskogo social'nogo instituta [Bulletin of the Prikamsky social Institute]. — 2018. — №1 (79). Pp. 109-113.

11. Dobryshina L.N. Social'no-jekonomicheskaja bezopasnost': sushhnost', jevoljucija, faktory [Socio-economic security: essence, evolution, factors] // Transportnoe delo Ros- 
sii [Transport business of Russia]. — 2011. №10. - Pp. 5-7.

12. Jekonomicheskaja bezopasnost' Rossii: metodologija, strategicheskoe upravlenie, sistemotehnika: monografija [Economic security of Russia: methodology, strategic management, system engineering: monograph] / In S. N. Sil'vestrov (ed.). - Moscow: RUSAJNS, 2018. - 350 p.

13. Samygin S. I., Stepanov O. V. Social'naja bezopasnost' v sisteme social'no-gumanitarnogo znanija o bezopasnosti [Social security in the system of social and humanitarian knowledge about security] // Social'no-gumanitarnye znanija [Social and humanitarian knowledge]. 2014. — №11. — Pp. 54-55.

14. SolozhencevE.D. Upravlenie bezopasnost'ju social'no-jekonomicheskih sistem [Managing the security of socio-economic systems]// Problemy analiza riska [Problems of risk analysis]. - 2017. - Vol. 14. - №5. - Pp. 6-19. [Jelektronnyj resurs]. - URL: https://doi. org/10.32686/1812-5220-2017-14-5-6-19.

15. Uskova T.V. Kljuchevye ugrozy jekonomicheskoj bezopasnosti Rossii [Key threats to Russia's economic security] // Problemy razvitija territorii [Problems of territory development]. 2019. — №1 (99). — Pp. 7-16.

16. Vodenko K.V., Borovaja L.V., Efimov A.V. Rossijskoe obrazovanie $\mathrm{v}$ uslovijah global'noj informatizacii i cifrovizacii: social'nofilosofskij diskurs [Russian education in the context of global Informatization and digitalization: socio-philosophical discourse] // Gumanitarij Juga Rossii [Humanities of the South of Russia]. - 2020. - Vol. 9. - №3. - Pp. 36- 44.

17. Kovalev V.V., Kas'janov V. V., Manucharjan $A$. K. Onlajn-obrazovanie v vysshej shkole Rossii: faktor razrushenija ili istochnik razvitija? [Online education in higher education in Russia: a factor of destruction or a source of development?] // Gumanitarij Juga Rossii [Humanities of the South of Russia]. — 2020. — Vol. 9. №3. - Pp. 72-91.

18. Feofanov K.E. O scenarnom podhode $\mathrm{k}$ prognozirovaniju [On scenario approach to forecasting] // Sociologicheskie issledovanija [Sociological research]. - 2008. — №5. - Pp. 67-74.

19. Volkov Ju. G., Vereshhagina A. V., Uzunov $V$. $V$. Scenarii innovacionnogo razvitija rossi- jskih regionov: institucional'no-upravlencheskoe izmerenie [Scenarios of innovative development of Russian regions: institutional and managerial dimension] // Gosudarstvennoe i municipal'noe upravlenie. Uchenye zapiski [State and municipal management. Scientific notes]. - 2019. №2. - Pp. 35-40.

20. Kortunov A. Global'naja pobeda nad COVID-19: my za cenoj ne postoim? [Global victory over COVID-19: we will not stand for the price?] [Jelektronnyj resurs]. — URL: https://russiancouncil.ru/analytics-and-comments/ analytics/globalnaya-pobeda-nad-covid-19-myza-tsenoy-ne-postoim/.

21. Kuznecov A. Koronavirus kak diagnoz sistemnogo zastoja [Coronavirus as a diagnosis of systemic stagnation] [Jelektronnyj resurs]. - URL: $\mathrm{https}$ ://russiancouncil.ru/analytics-and-comments/ analytics/koronavirus-kak-diagnoz-sistemnogozastoya/.

22. Koronakrizis-2020: chto budet i chto delat'? Scenarii razvitija i mery jekonomicheskoj politiki [Coronaries-2020: what will happen and what to do? Scenarios of development and measures of economic policy] / In K. Rogov (ed.). Moscow: Liberal'naja missija, 2020. — 45 p.

23. Beljaeva $S$. O zhizni posle: jeksperty zagljanuli $\mathrm{V}$ postpandemicheskuju real'nost' [About life after: experts looked into the posttandem reality] [Jelektronnyj resurs]. - URL: https://www.poisknews.ru/themes/ekonomika/ o-zhizni-posle-eksperty-zaglyanuli-v-postpandemicheskuyu-realnost/.

24. Bagdasarjan $V$. Koronavirusnyj mir: postpandemicheskie modeli [Coronavirus world: postpandemic models] [Jelektronnyj resurs]. URL: http://www.noravank.am/rus/articles/detail.php? ELEMENT_ID=18066.

25. Virusnyj avtoritarizm [Viral authoritarianism] [Jelektronnyj resurs]. - URL: http:// www.eedialog.org/ru/2020/04/29/virusnyj-avtoritarizm/.

26. Evstaf'ev D., Il'nickij A. Predpolozhenija o grjadushhem mire [Assumptions about the future world] // Rossija v global'noj politike [Russia in global politics]. — 2020. — №4. [Jelektronnyj resurs]. — URL: https://globalaffairs.ru/articles/predpolozheniya-o-gryadushhem-mire/. 


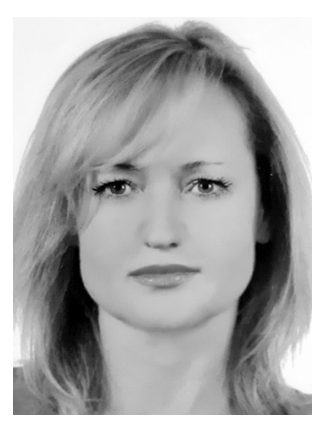

Верещагина Анна Владимировна - доктор социологических наук, доцент, профессор Института социологии и регионоведения Южного федерального университета.

Vereshchagina Anna Vladimirovna - Doctor of Sociological Sciences, Professor, Professor, Institute of Sociology and Regional Studies, Southern Federal University.

344006, г. Ростов-на-Дону, ул. Пушкинская, 160 160 Pushkinskaya st., 344006, Rostov-on-Don, Russia E-mail: anrietta25@mail.ru

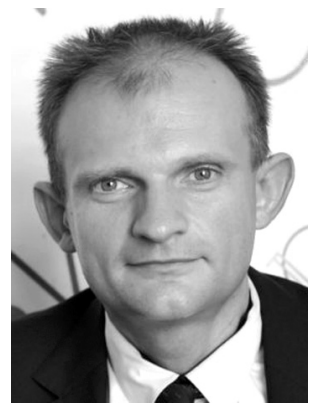

Рачипа Андрей Валерьевич - доктор социологических наук, профессор, заведующий кафедрой социологии, истории и политологии Института управления в экономических, экологических и социальных системах Южного федерального университета, профессор-совместитель кафедры 109Б Московского авиационного института (Национального исследовательского университета) в г. Москве.

Rachipa Andrey Valerievich - Doctor of Sociological Sciences, Professor, Head of the Department of Sociology, History and Political Science, Institute of Management in Economic, Environmental and Social Systems, Southern Federal University, part-time Professor of the Department 109B of the Moscow Aviation Institute (National Research University) in Moscow.

347900 , г. Таганрог, ул. Энгельса, 1

1 Engelsa st., 347900, Taganrog, Russia

E-mail: rachipa@sfedu.ru 


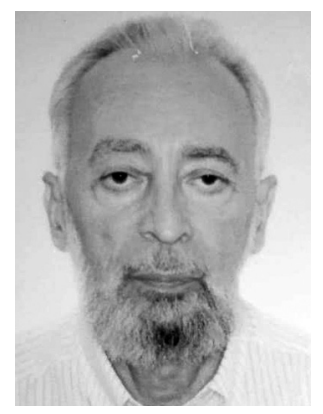

Таранов Петр Владимирович — профессор, доктор экономических наук, профессор кафедры Международной торговли и таможенного дела Ростовского государственного экономического университета (РИНХ).

Taranov Pyotr Vladimirovich - Professor, Doctor of Economic Sciences, Professor of the Department of International Trade and Customs, Rostov State University of Economics (RSUE).

344002, г. Ростов-на-Дону, ул. Большая Садовая, 69

69 Bolshaya Sadovaya st., 344002, Rostov-on-Don, Russia

E-mail: petr.taranov.52@mail.ru 